\title{
Insecticide resistance to insect growth regulators, avermectins, spinosyns and diamides in Culex quinquefasciatus in Saudi Arabia
}

\author{
Abdulwahab M. Hafez (10) and Naeem Abbas*
}

\begin{abstract}
Background: Culex quinquefasciatus is not only a biting nuisance but also an important vector of fatal diseases. In Saudi Arabia, management measures to control this mosquito and thereby prevent associated disease transmission have focused on insecticides. Nevertheless, information on the resistance status of $C$. quinquefasciatus is insufficient, especially concerning insecticides containing novel classes of insecticides.
\end{abstract}

Methods: We evaluated six insecticides belonging to four classes of insecticides (insect growth regulators [3], avermectins [1], diamides [1] and spinosyns [1]) for toxicity and resistance in eight C. quinquefasciatus populations (from Ishbiliya, Al-Masfa, Al-Masanie, Al-Washlah, Al-Nakhil, Irqah, Al-Suwaidi and Al-Ghanemiya) following World Health Organisation protocols.

Results: Resistance status ranging from susceptibility/low resistance to high resistance, in comparison with the susceptible strain, was detected for cyromazine in the eight $C$. quinquefasciatus populations: Ishbiliya (resistance ratio $[R R]=3.33)$, Al-Masfa ( $R R=4.33)$, Al-Masanie $(R R=3.67)$, Al-Washlah $(R R=2.33)$, Al-Nakhil $(R R=5.33)$, Irqah $(R R=$ 7.00), Al-Suwaidi $(R R=21.33)$ and Al-Ghanemiya $(R R=16.00)$. All C. quinquefasciatus populations exhibited a high level of resistance to diflubenzuron ( $R R=13.33-43.33)$, with the exception of Al-Nakhil which exhibited moderate resistance $(R R=10.00)$. Susceptibility/low resistance to high resistance was observed for triflumuron in the eight C. quinquefasciatus populations: Ishbiliya ( $R R=0.50)$, Al-Ghanemiya $(R R=3.00)$, Al-Suwaidi $(R R=10.00)$, Al-Masfa $(R R=5.00)$, Al-Masanie $(R R=10.00)$, Al-Nakhil $(R R=5.00)$, Irqah $(R R=5.00)$ and Al-Washlah $(R R=15.00)$. Susceptibility/low resistance was assessed for abamectin, chlorantraniliprole and spinosad in all C. quinquefasciatus populations, with RR ranges of $0.25-3.50,0.17-2.19$, and $0.02-0.50$, respectively. However, the population collected from Irqah showed high resistance to chlorantraniliprole $(R R=11.93)$.

Conclusions: The detection of widespread resistance to insect growth regulators in C. quinquefasciatus highlights an urgent need to establish integrated vector management strategies. Our results may facilitate the selection of potent insecticides for integrated vector management programmes for C. quinquefasciatus.

Keywords: Mosquitoes, Field-evolved-resistance, Diflubenzuron, Chlorantraniliprole, Biopesticides, Insect vector management

*Correspondence: hafez@ksu.edu.sa; nnoor.c@ksu.edu.sa

Pesticides and Environmental Toxicology Laboratory, Department

of Plant Protection, College of Food and Agriculture Sciences, King Saud

University, P.O. Box 2460, Riyadh 11451, Saudi Arabia

(c) The Author(s) 2021. Open Access This article is licensed under a Creative Commons Attribution 4.0 International License, which permits use, sharing, adaptation, distribution and reproduction in any medium or format, as long as you give appropriate credit to the original author(s) and the source, provide a link to the Creative Commons licence, and indicate if changes were made. The images or other third party material in this article are included in the article's Creative Commons licence, unless indicated otherwise in a credit line to the material. If material is not included in the article's Creative Commons licence and your intended use is not permitted by statutory regulation or exceeds the permitted use, you will need to obtain permission directly from the copyright holder. To view a copy of this licence, visit http://creativecommons.org/licenses/by/4.0/. The Creative Commons Public Domain Dedication waiver (http://creativeco mmons.org/publicdomain/zero/1.0/) applies to the data made available in this article, unless otherwise stated in a credit line to the data. 


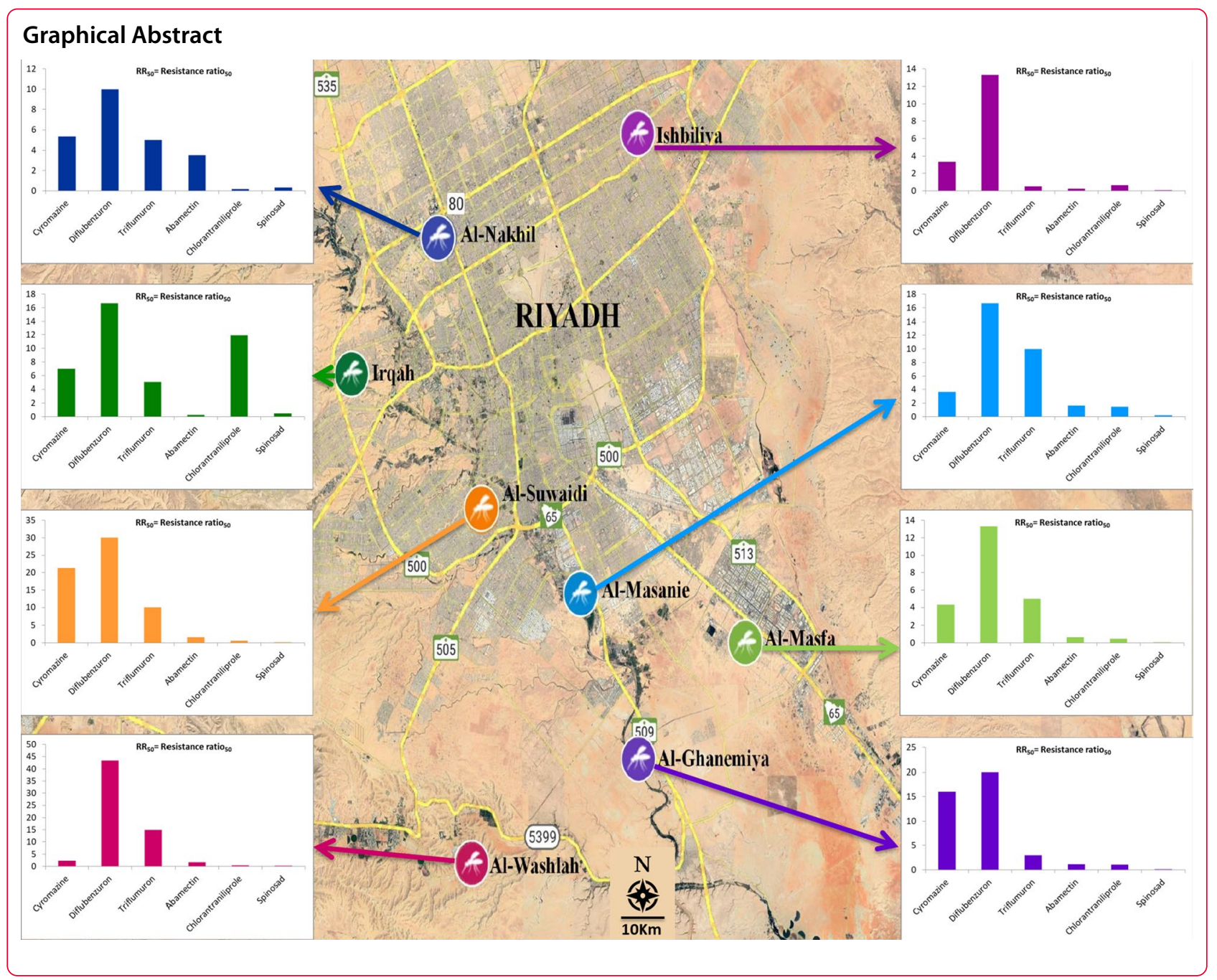

\section{Background}

Culex quinquefasciatus is not only a biting nuisance to its hosts [1,2] but also a significant insect vector of various parasites, including West Nile fever, lymphatic filariasis and Japanese encephalitis [3-5]. Culex quinquefasciatus can breed in various aquatic habitats, including mangrove swamps, fresh or salt water marshes, stream and river edges and temporary standing rain water [6-8], and human settlements, agricultural lands and livestock farms with inadequate hygienic practices/facilities are also ideal breeding habitats.

Management measures, such as the use of genetic manipulation, sterile insect techniques, eradication of breeding places, chemical insecticides and natural biological agents, have been used to control insect vectors, including C. quinquefasciatus, worldwide $[1,9,10]$. Of these, the management of $C$. quinquefasciatus to prevent associated parasite transmission has focused on insecticides as a rapid control measure [11, 12]. At the present time, avermectins, diamides and spinosyns, are being used widely to control the larvae of $C$. quinquefasciatus and other insect vectors worldwide $[1,13,14]$. However, the extensive and widespread use of these insecticides has led to resistance in C. quinquefasciatus in different parts of the world [1, 15-19] and, in adddition, has caused environmental pollution, increases in the preventive costs of chemical control and destroyed nontarget organisms [20-22]. Taken together, these factors necessitate the use of integrated vector management programmes against $C$. quinquefasciatus.

The IGRs cyromazine, diflubenzuron and triflumuron are currently the most effective larvicides for controlling mainly dipteran pests, including mosquitoes [13, 23-25]. Cyromazine is a molting disruptor, whereas diflubenzuron and triflumuron are chitin synthesis inhibitors. Abamectin (an avermectin) and spinosad (a spinosyn) are biorational insecticides, with the former being a glutamate-gated chloride channel allosteric modulator and the 
latter a nicotinic acetylcholine receptor allosteric modulator [26]. Chlorantraniliprole is an anthranilic diamide insecticide; it acts as a ryanodine receptor modulator in insect muscles [26], causing the uncontrolled release of calcium ions that leads to feeding cessation, lethargy, muscle paralysis and ultimately death [27, 28]. Because of their low mammalian toxicity and low hazard threat to the target's natural enemies, these insecticides are good candidates for the management of various insect pests, including mosquitoes [29-31].

Mosquito control programmes in Riyadh, Saudi Arabia rely mainly on chemical control. Consequently, there is always the possibility of the development of insecticide resistance, which would, for example, reduce the effectiveness of chemical control against $C$. quinquefasciatus. It is crucial to know the resistance status of $C$. quinquefasciatus to newly developed insecticides before their widespread use in Riyadh (Fig. 1). Hence, we evaluated the toxicity and resistance levels of six novel insecticides in the IGR, avermectin, diamide, and spinosyn classes against eight $C$. quinquefasciatus larval populations from different areas in Riyadh, Saudi Arabia. Baseline susceptibility data from this study will help in the design of appropriate and effective strategies for controlling $C$. quinquefasciatus.

\section{Methods \\ Culex quinquefasciatus populations}

Approximately 200 C. quinquefasciatus larvae at mixed developmental stages were collected from standing water or from containers at each of the eight different study locations in the environs of Riyadh, Saudi Arabia; these sites were designated ISH, SUW, GHN, MSF, MSN, NKL, WSH and IRQ (Fig. 1; Table 1). The locations were selected on the basis that there was a high chance they had been exposed to pesticides. Each population was collected and maintained separately. After collection, larvae of each population were transferred to alternative plastic containers $(4 \mathrm{l})$ in the laboratory and provided cattle food ad libitum for feeding until pupation. The emerged adults were transferred into cages $(30 \times 30 \mathrm{~cm})$, and cotton wicks soaked in $10 \%$ sugar solution were provided as food. The cotton wicks were moistened every 2 days and replaced when they became dirty. A restrained pigeon

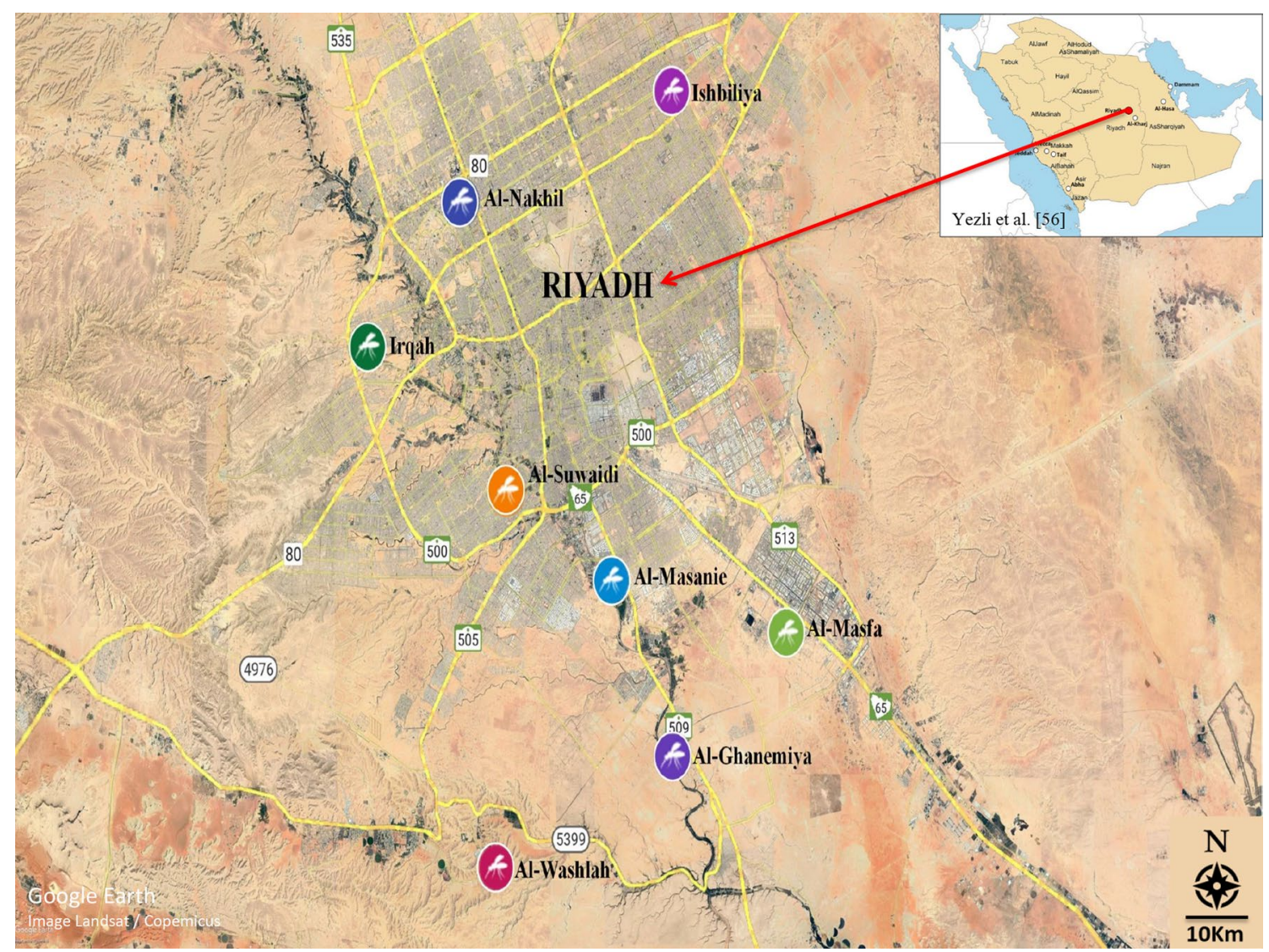

Fig. 1 Location of sites where Culex quinquefasciatus field populations were collected in Riyadh city. See Table 1 for abbreviations of study/ population collection sites 
Table 1 History of Culex quinquefasciatus field populations collected from Riyadh city

\begin{tabular}{|c|c|c|c|c|}
\hline Population & Location & Coordinates & Collection month, year & $\begin{array}{l}\text { Number of larvae } \\
\text { (approximate } \\
\text { estimate) }\end{array}$ \\
\hline $\mathrm{ISH}$ & Ishbiliya & $24.802^{\circ} \mathrm{N}, 46.803^{\circ} \mathrm{E}$ & January, 2020 & 200 \\
\hline SUW & Al-Suwaidi & $24.590^{\circ} \mathrm{N}, 46.676^{\circ} \mathrm{E}$ & January, 2020 & 200 \\
\hline GHN & Al-Ghanemiya & $24.482^{\circ} \mathrm{N}, 46.798^{\circ} \mathrm{E}$ & January, 2020 & 200 \\
\hline MSF & Al-Masfa & $24.471^{\circ} \mathrm{N}, 46.861^{\circ} \mathrm{E}$ & January, 2020 & 200 \\
\hline MSN & Al-Masanie & $24.558^{\circ} \mathrm{N}, 46.743^{\circ} \mathrm{E}$ & January, 2020 & 200 \\
\hline$N K L$ & Al-Nakhil & $24.737^{\circ} \mathrm{N}, 46.620^{\circ} \mathrm{E}$ & January, 2020 & 200 \\
\hline WSH & Al-Washlah & $24.409^{\circ} \mathrm{N}, 46.660^{\circ} \mathrm{E}$ & January, 2020 & 200 \\
\hline IRQ & Irqah & $24.677^{\circ} \mathrm{N}, 46.575^{\circ} \mathrm{E}$ & January, 2020 & 200 \\
\hline
\end{tabular}

with keel feathers removed was provided for $12 \mathrm{~h}$ overnight for blood-feeding during each oviposition period. Plastic cups $(500 \mathrm{ml})$ containing tap water were placed in the adult cages to receive egg masses and to obtain uniform $F_{1}$ populations. The plastic cups were then removed and the eggs transferred into plastic containers. Hatched larvae were provided with cattle food ad libitum and third-instar larvae were used for the bioassay. All populations were maintained separately in the laboratory at $27^{\circ} \mathrm{C} \pm 2{ }^{\circ} \mathrm{C}, 65 \% \pm 5 \%$ humidity and under a $12: 12 \mathrm{~h}$ (light: dark) photoperiod.

The susceptible reference strain (designated as SUS) was obtained from the High Institute of Public Health, Alexandria University, Egypt, in 1990 and has been maintained since then under the above-mentioned protocol with no exposure to any kind of chemicals.

\section{Insecticides}

The following six commonly used commercial formulations of insecticides belonging to four classes were used for larval bioassays: (i) the IGRs cyromazine (Novasat 75WP; Astranova Chemicals, Antalya, Turkey), diflubenzuron (Diflon 250WP; Saudi Delta Company, Riyadh, Saudi Arabia) and triflumuron (Starycide 480SC; Bayer CropScience, St. Louis, MO, USA); (ii) the avermectin abamectin (Malactin 36EC; Shams Badeel Factory, Riyadh, Saudi Arabia); (iii) the diamide chlorantraniliprole (Coragen 20SC; FMC Corp., Philadelphia, PA, USA); and (iv) the spinosyn spinosad (Tracer 40SC; Dow AgroSciences Ltd., Abingdon, UK).

\section{Larva bioassays}

The bioassays of the insecticides against $C$. quinquefasciatus larvae were performed following the protocol proposed by the World Health Organisation [32]. For each insecticide, five concentrations that caused mortality ranging from $>0 \%$ to $<100 \%$ were prepared in tap water by serial dilution from a stock solution $(1000 \mathrm{ml})$. A fresh stock solution was prepared for each replication, and assays were performed at different times to ensure true replication [33]. Third-instar larvae from each pooled population were kept in plastic cups containing $400 \mathrm{ml}$ of the test solution. Insecticide dilution bioassays were performed four times, with 10 larvae per replicate and a total of 240 larvae in each bioassay. A total of 40 larvae (four replicates/9 larvae in each) were used in the control treatment. All bioassays were conducted and maintained under the above-mentioned laboratory conditions. Mortality was recorded after $48 \mathrm{~h}$ for the abamectin, chlorantraniliprole and spinosad treatment groups. For the three IGR groups, mortality data were recorded after adult emergence, with pupae failing to emerge as adults considered to be dead.

\section{Data analyses}

The bioassay data were analysed using POLO Plus software [34] to determine the median lethal concentration $\left(\mathrm{LC}_{50}\right)$, 95\% fiducial limits (FLs), standard error, and chi-squared $\left(x^{2}\right)$ test. Using the Abbott [35] formula, mortalities were corrected when needed by reference to mortality in the control treatment. $\mathrm{LC}_{50}$ values were considered to be significantly different if their 95\% FLs did not overlap [36]. Resistance ratios (RRs) were calculated as: $\mathrm{LC}_{50}$ for the field population/ $/ \mathrm{LC}_{50}$ for the susceptible strain. The RRs were classified as follows: $R R<5$ indicated susceptibility/low resistance; $R R=5-10$ indicated moderate resistance and $R R>10$ indicated high resistance [32, 37].

\section{Results}

\section{Resistance to IGRs}

The $\mathrm{LC}_{50}$ and $\mathrm{RR}$ values for the IGRs cyromazine, diflubenzuron and triflumuron for the eight $C$. quinquefasciatus field larval populations are reported in Table 2.

The $\mathrm{LC}_{50}$ for cyromazine ranged from 0.007 to $0.064 \mu \mathrm{g} / \mathrm{ml}$. The populations ISH, MSF, MSN and WSH showed susceptibility/low resistance to cyromazine $(R R=3.33,4.33,3.67$ and 2.33 , respectively); two field 
populations, namely NKL and IRQ, showed moderate resistance $(R R=5.33$ and 7.00 , respectively) and the SUW and GHN field populations showed high resistance $(R R=21.33$ and 16.00 , respectively).

The $\mathrm{LC}_{50}$ values for diflubenzuron ranged from 0.003 to $0.013 \mu \mathrm{g} / \mathrm{ml}$. All populations exhibited a high level of resistance to diflubenzuron $(R R=13.33-43.33)$, except for NKL, which exhibited moderate resistance $(\mathrm{RR}=10.00)$.

The $\mathrm{LC}_{50}$ values for triflumuron ranged from 0.0001 to $0.003 \mu \mathrm{g} / \mathrm{ml}$. The WSH population showed high resistance $(R R=15)$, the SUW, MSF, MSN, NKL and IRQ populations showed moderate resistance $(R R=10.00,5.00$, $10.00,5.00$ and 5.00, respectively) ISH and the GHN population showed susceptibility/low resistance $(R R=0.50$ and 3.00 , respectively).
Resistance to abamectin, chlorantraniliprole and spinosad The $\mathrm{LC}_{50}$ and $\mathrm{RR}$ values for abamectin, chlorantraniliprole and spinosad for the eight $C$. quinquefasciatus field larval populations are reported in Table 3.

The $\mathrm{LC}_{50}$ for abamectin ranged from 0.002 to $0.028 \mu \mathrm{g} /$ $\mathrm{ml}$, and the RRs ranged from 0.25 to 3.50 for all eight field populations, indicating that all populations were susceptible/showed low resistance to abamectin.

The $\mathrm{LC}_{50}$ for chlorantraniliprole ranged from 0.005 to $0.346 \mu \mathrm{g} / \mathrm{ml}$ and the RRs ranged from 0.17 to 11.93 . Susceptibility/low resistance was observed in all field populations with the exception of the IRQ population, which showed high resistance to chlorantraniliprole.

The $\mathrm{LC}_{50}$ for spinosad ranged from 0.0002 to $0.006 \mu \mathrm{g} /$ $\mathrm{ml}$, and the RRs ranged from 0.02 to 0.50 , indicating that all field populations exhibited susceptibility/low resistance to spinosad.

Table 2 Resistance to insect growth regulators in Culex quinquefasciatus larva populations from Riyadh city

\begin{tabular}{|c|c|c|c|c|c|c|c|c|c|}
\hline Insecticide & Population $^{a}$ & $n$ & Concentration $(\mu \mathrm{g} / \mathrm{ml})$ & $\mathrm{LC}_{50}(95 \% \mathrm{FL})(\mathrm{mg} / \mathrm{ml})$ & Slope \pm SE & $x^{2}$ & $d f$ & P & $\mathrm{RR}$ \\
\hline \multirow[t]{9}{*}{ Cyromazine } & SUS & 240 & $0.0010-0.0156$ & $0.003(0.002-0.004)$ & $1.78 \pm 0.25$ & 0.66 & 3 & 0.88 & 1.00 \\
\hline & ISH & 240 & $0.0039-0.0625$ & $0.010(0.008-0.013)$ & $1.84 \pm 0.26$ & 3.27 & 3 & 0.35 & 3.33 \\
\hline & SUW & 240 & $0.0039-0.0625$ & $0.064(0.037-0.222)$ & $0.99 \pm 0.24$ & 0.73 & 3 & 0.87 & 21.33 \\
\hline & GHN & 240 & $0.0039-0.0625$ & $0.048(0.024-0.476)$ & $0.65 \pm 0.22$ & 0.38 & 3 & 0.94 & 16.00 \\
\hline & MSF & 240 & $0.0039-0.0625$ & $0.013(0.008-0.019)$ & $1.04 \pm 0.22$ & 0.68 & 3 & 0.88 & 4.33 \\
\hline & MSN & 240 & $0.0039-0.0625$ & $0.011(0.005-0.018)$ & $0.80 \pm 0.22$ & 0.61 & 3 & 0.89 & 3.67 \\
\hline & NKL & 240 & $0.0039-0.0625$ & $0.016(0.012-0.022)$ & $1.45 \pm 0.23$ & 0.95 & 3 & 0.81 & 5.33 \\
\hline & WSH & 240 & $0.0039-0.0625$ & $0.007(0.001-0.015)$ & $0.60 \pm 0.21$ & 0.13 & 3 & 0.99 & 2.33 \\
\hline & IRQ & 240 & $0.0039-0.0625$ & $0.021(0.013-0.045)$ & $0.80 \pm 0.22$ & 0.04 & 3 & 1.00 & 7.00 \\
\hline \multirow[t]{9}{*}{ Diflubenzuron } & SUS & 240 & $0.0001-0.0020$ & $0.0003(0.0002-0.0004)$ & $1.37 \pm 0.23$ & 0.99 & 3 & 0.80 & 1.00 \\
\hline & ISH & 240 & $0.0020-0.0313$ & $0.004(0.003-0.005)$ & $1.90 \pm 0.27$ & 5.56 & 3 & 0.14 & 13.33 \\
\hline & SUW & 240 & $0.0039-0.0625$ & $0.009(0.007-0.011)$ & $2.30 \pm 0.30$ & 3.08 & 3 & 0.38 & 30.00 \\
\hline & $\mathrm{GHN}$ & 240 & $0.0039-0.0625$ & $0.006(0.004-0.008)$ & $1.59 \pm 0.26$ & 1.62 & 3 & 0.65 & 20.00 \\
\hline & MSF & 240 & $0.0039-0.0625$ & $0.004(0.002-0.007)$ & $1.15 \pm 0.25$ & 1.49 & 3 & 0.68 & 13.33 \\
\hline & MSN & 240 & $0.0039-0.0625$ & $0.005(0.002-0.007)$ & $1.42 \pm 0.26$ & 1.50 & 3 & 0.68 & 16.67 \\
\hline & NKL & 240 & $0.0039-0.0625$ & $0.003(0.001-0.006)$ & $1.18 \pm 0.25$ & 3.38 & 3 & 0.34 & 10.00 \\
\hline & WSH & 240 & $0.0039-0.0625$ & $0.013(0.010-0.017)$ & $1.80 \pm 0.25$ & 0.34 & 3 & 0.95 & 43.33 \\
\hline & IRQ & 240 & $0.0039-0.0625$ & $0.005(0.004-0.007)$ & $2.28 \pm 0.35$ & 3.07 & 3 & 0.38 & 16.67 \\
\hline \multirow[t]{9}{*}{ Triflumuron } & SUS & 240 & $0.00003-0.0005$ & $0.0002(0.0001-0.0002)$ & $1.81 \pm 0.33$ & 1.76 & 3 & 0.62 & 1.00 \\
\hline & ISH & 240 & $0.00002-0.0002$ & $0.0001(0.00004-0.0001)$ & $1.90 \pm 0.26$ & 1.85 & 3 & 0.60 & 0.50 \\
\hline & SUW & 240 & $0.0005-0.0078$ & $0.002(0.000-0.007)$ & $0.51 \pm 0.21$ & 1.58 & 3 & 0.66 & 10.00 \\
\hline & $\mathrm{GHN}$ & 240 & $0.0005-0.0078$ & $0.0006(0.0003-0.0009)$ & $1.51 \pm 0.29$ & 4.56 & 3 & 0.21 & 3.00 \\
\hline & MSF & 240 & $0.0005-0.0078$ & $0.001(0.000-0.001)$ & $1.04 \pm 0.24$ & 0.12 & 3 & 0.99 & 5.00 \\
\hline & MSN & 240 & $0.0005-0.0039$ & $0.002(0.001-0.003)$ & $1.25 \pm 0.31$ & 1.08 & 2 & 0.78 & 10.00 \\
\hline & NKL & 240 & $0.0005-0.0078$ & $0.001(0.001-0.002)$ & $1.46 \pm 0.24$ & 4.21 & 3 & 0.24 & 5.00 \\
\hline & WSH & 240 & $0.0005-0.0078$ & $0.003(0.002-0.004)$ & $1.28 \pm 0.23$ & 2.29 & 3 & 0.51 & 15.00 \\
\hline & IRQ & 240 & $0.0005-0.0078$ & $0.001(0.001-0.002)$ & $0.78 \pm 0.22$ & 0.31 & 3 & 0.96 & 5.00 \\
\hline
\end{tabular}

${ }^{\text {a }}$ See Table 1 for the full names of each study population/study location

$\mathrm{FL}$, fiducial limits; $\mathrm{LC}_{50}$, median lethal concentration; $n$, number of larvae exposed in each bioassay; $\mathrm{SE}$, standard error; $\mathrm{RR}$, resistance ratio ( $\mathrm{LC} \mathrm{C}_{50}$ of insecticide for the field population/ $/ \mathrm{LC}_{50}$ of insecticide for the susceptible strain) 
Table 3 Resistance to abamectin, chlorantraniliprole and spinosad in Culex quinquefasciatus larval populations from Riyadh city

\begin{tabular}{|c|c|c|c|c|c|c|c|c|c|}
\hline Insecticide & Population $^{\mathrm{a}}$ & $n$ & Concentration $(\mu \mathrm{g} / \mathrm{ml})$ & $\mathrm{LC}_{50}(95 \% \mathrm{FL})(\mathrm{mg} / \mathrm{ml})$ & Slope \pm SE & $x^{2}$ & $d f$ & $P$ & RR \\
\hline \multirow[t]{9}{*}{ Abamectin (avermectin class) } & SUS & 240 & $0.0020-0.0625$ & $0.008(0.006-0.010)$ & $1.42 \pm 0.19$ & 1.83 & 4 & 0.77 & 1.00 \\
\hline & $\mathrm{ISH}$ & 240 & $0.0010-0.0156$ & $0.002(0.001-0.004)$ & $0.94 \pm 0.21$ & 0.47 & 3 & 0.93 & 0.25 \\
\hline & SUW & 240 & $0.0020-0.0625$ & $0.013(0.009-0.020)$ & $1.34 \pm 0.21$ & 2.98 & 4 & 0.56 & 1.63 \\
\hline & GHN & 240 & $0.0020-0.0625$ & $0.009(0.007-0.012)$ & $1.85 \pm 0.24$ & 3.76 & 4 & 0.44 & 1.13 \\
\hline & MSF & 240 & $0.0039-0.0625$ & $0.005(0.002-0.007)$ & $1.28 \pm 0.29$ & 0.50 & 3 & 0.92 & 0.63 \\
\hline & MSN & 240 & $0.0020-0.0625$ & $0.013(0.008-0.021)$ & $1.01 \pm 0.20$ & 1.70 & 4 & 0.79 & 1.63 \\
\hline & NKL & 240 & $0.0039-0.0625$ & $0.028(0.015-0.099)$ & $0.79 \pm 0.25$ & 0.20 & 3 & 0.98 & 3.50 \\
\hline & WSH & 240 & $0.0039-0.0625$ & $0.013(0.009-0.018)$ & $1.22 \pm 0.23$ & 1.05 & 3 & 0.79 & 1.63 \\
\hline & IRQ & 240 & $0.0010-0.0156$ & $0.002(0.001-0.004)$ & $0.78 \pm 0.25$ & 1.16 & 3 & 0.76 & 0.25 \\
\hline \multirow[t]{9}{*}{ Chlorantraniliprole (diamide class) } & SUS & 240 & $0.0020-0.0625$ & $0.029(0.020-0.046)$ & $1.26 \pm 0.19$ & 3.15 & 4 & 0.53 & 1.00 \\
\hline & $\mathrm{ISH}$ & 240 & $0.0078-0.125$ & $0.018(0.000-0.051)$ & $0.51 \pm 0.24$ & 0.43 & 3 & 0.93 & 0.62 \\
\hline & SUW & 240 & $0.0020-0.0625$ & $0.018(0.014-0.024)$ & $1.95 \pm 0.26$ & 0.87 & 4 & 0.93 & 0.62 \\
\hline & GHN & 240 & $0.0020-0.0625$ & $0.030(0.020-0.055)$ & $1.21 \pm 0.22$ & 3.81 & 4 & 0.43 & 1.03 \\
\hline & MSF & 240 & $0.0020-0.0625$ & $0.013(0.008-0.021)$ & $1.01 \pm 0.20$ & 0.11 & 4 & 0.99 & 0.45 \\
\hline & MSN & 240 & $0.0020-0.0625$ & $0.042(0.024-0.121)$ & $0.95 \pm 0.21$ & 0.44 & 4 & 0.98 & 1.45 \\
\hline & NKL & 240 & $0.0039-0.0625$ & $0.005(0.000-0.011)$ & $0.62 \pm 0.25$ & 0.62 & 3 & 0.89 & 0.17 \\
\hline & WSH & 240 & $0.0039-0.0625$ & $0.012(0.009-0.015)$ & $1.85 \pm 0.27$ & 1.52 & 3 & 0.68 & 0.41 \\
\hline & IRQ & 240 & $0.2500-4.0000$ & $0.346(0.204-0.482)$ & $1.54 \pm 0.26$ & 0.15 & 3 & 0.99 & 11.93 \\
\hline \multirow[t]{9}{*}{ Spinosad (spinosyn class) } & SUS & 240 & $0.0001-0.0039$ & $0.012(0.004-0.511)$ & $0.61 \pm 0.18$ & 0.66 & 4 & 0.96 & 1.00 \\
\hline & $\mathrm{ISH}$ & 240 & $0.0020-0.0313$ & $0.001(0.000-0.003)$ & $0.71 \pm 0.21$ & 0.58 & 3 & 0.90 & 0.08 \\
\hline & SUW & 240 & $0.0001-0.0039$ & $0.0003(0.0002-0.0004)$ & $2.25 \pm 0.30$ & 5.58 & 4 & 0.23 & 0.03 \\
\hline & GHN & 240 & $0.0001-0.0039$ & $0.0003(0.0002-0.0004)$ & $1.97 \pm 0.28$ & 1.15 & 4 & 0.89 & 0.03 \\
\hline & MSF & 240 & $0.0001-0.0039$ & $0.001(0.0006-0.0014)$ & $2.59 \pm 0.53$ & 4.82 & 4 & 0.31 & 0.08 \\
\hline & MSN & 240 & $0.0020-0.0625$ & $0.002(0.002-0.003)$ & $2.68 \pm 0.50$ & 1.38 & 4 & 0.85 & 0.17 \\
\hline & NKL & 240 & $0.0002-0.0039$ & $0.004(0.003-0.009)$ & $1.58 \pm 0.33$ & 2.27 & 3 & 0.52 & 0.33 \\
\hline & WSH & 240 & $0.0002-0.0039$ & $0.0002(0.0001-0.0004)$ & $1.10 \pm 0.28$ & 0.35 & 3 & 0.95 & 0.02 \\
\hline & IRQ & 240 & $0.0020-0.0313$ & $0.006(0.003-0.010)$ & $1.00 \pm 0.26$ & 1.11 & 3 & 0.77 & 0.50 \\
\hline
\end{tabular}

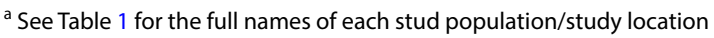

\section{Discussion}

Information on the susceptibility status of insect vectors to commonly used insecticides is a key aspect in the selection of the most appropriate and effective insecticide $[13,38,39]$. In this study, the eight $C$. quinquefasciatus populations showed varying levels of resistance, ranging from low to high, against cyromazine. Cases of resistance to cyromazine have been documented in various medical and veterinary pests around the world. For example, different levels of cyromazine resistance have been found in the house fly Musca domestica $(\mathrm{RR}=4.8$ [40], $\mathrm{RR}=62.5$ [41], $\mathrm{RR}=5.6$ [42], $\mathrm{RR}=18.0$ [43, 44] and $\mathrm{RR}=2.9$ [13]) and in the Australian sheep blowfly Lucilia cuprina $(\mathrm{RR}=12.8[45])$.

In the present study, all test populations of $C$. quinquefasciatus exhibited a high level of resistance to the IGR diflubenzuron; in contrast, for the IGR triflumuron, one population showed high resistance, five showed moderate resistance and two showed susceptibility/low resistance. Diflubenzuron has been found to be an effective IGR against the stable fly Stomoxys calcitrans and the mosquitoes Aedes aegypti and Aedes albopictus [23-25]. However, a high level of diflubenzuron resistance was found in $M$. domestica $(\mathrm{RR}=120)$ [40], in the sheep body louse Bovicola ovis $(\mathrm{RR}=90)[46]$ and in the mosquito Culex pipiens $(\mathrm{RR}=128)$ [47]. Similarly, triflumuron resistance has been well documented in B. ovis $(R R=93.8)$ [46]. Triflumuron has been found found to be an effective IGR against $M$. domestica $[13,44]$ and against $C$. quinquefasciatus [48].

Susceptibility/low resistance to the avermectin abamectin was detected in the $C$. quinquefasciatus populations in the present study. Previously, resistance to abamectin has been documented in $M$. domestica $(\mathrm{RR}=5.9-94.4)[22,49]$.

We also detected susceptibility/low resistance to diamide chlorantraniliprole in all $C$. quinquefasciatus populations from the tested regions, with the exception of the IRQ population which showed high resistance $(R R=11.93)$ when compared with the susceptible strain. 
Previously, field-evolved resistance to chlorantraniliprole has been reported in M. domestica $(\mathrm{RR}=36)$ [28].

In this study, susceptibility/low resistance to the spinosyn spinosad was detected in the $C$. quinquefasciatus populations from the tested regions. Field-evolved resistance to spinosad has been reported in $M$. domestica $(\mathrm{RR}=7.2)[22]$.

The evolution of insecticide resistance arises when a population has been intensively exposed to a pesticide, resulting in the elimination of susceptible individuals and the survival of resistant ones [21]. In this study, susceptibility/low resistance to abamectin, chlorantraniliprole and spinosad is an interesting finding and could could reflect the low or absence of usage of these insecticides against mosquitoes in Saudi Arabia, although insecticides with such novel formulations are commonly used against agricultural insect pests in Saudi Arabia.

This study highlights high levels of resistance in $C$. quinquefasciatus to diflubenzuron and triflumuron, possibly due to: (i) cross-resistance arising from concurrent usage of conventional insecticides like organophosphates and pyrethroids [13]; (ii) target-site mutations or involvement of metabolic enzymes [47, 50-52]; (iii) extensive usage of these insecticides in mosquito control programmes [53]; (iv) detoxification by enzymes [54, 55]; and/or (v) lack of effective and successful resistance management strategies [21]. Resistance to cyromazine is emerging in some C. quinquefasciatus populations, so this insecticide should be used rotationally in those locations where resistance has developed to delay further development of resistance. Nevertheless, further studies on cross-resistance patterns, metabolic mechanisms and target-site resistance mutations will confirm the exact phenomena. Laboratory selection of $C$. quinquefasciatus under the influence of diflubenzuron is currently under evaluation to explore cross-resistance and the mechanisms of resistance.

\section{Conclusions}

In conclusion, the evidence from this study of resistance to the IGRs cyromazine, diflubenzuron and triflumuron in C. quinquefasciatus indicates the potential lack of systematic management practices in Saudi Arabia. We believe that it is necessary to urgently establish effective resistance management strategies to delay the further development of resistance to these IGRs. Resistance management strategies, including the rotational use of potent insecticides, the integration of cultural practices, such as removal of breeding places, and the use of biological control agents [9], should be applied for the management of C. quinquefasciatus to minimise over-reliance on insecticides. The susceptibility/low resistance of $C$. quinquefasciatus larvae to abamectin, chlorantraniliprole, and spinosad suggests that these insecticides retain good potency and hence should be used rotationally with IGRs to sustain their efficacy. Periodic monitoring of resistance to these insecticides should be continued to detect any further increases in resistance. The findings of this study can serve as a reference in future monitoring efforts of $C$. quinquefasciatus insecticide susceptibility.

\section{Acknowledgements \\ The authors extend their appreciation to the Deanship of Scientific Research at King Saud University for funding this work through Research Group number $\mathrm{G}-1441-480$. The authors would like to thank the researchers and technicians from the Pesticides and Environmental Toxicology Laboratory, specifically Mohammed Ali Albaqiyah and Safwat Gamal Hassan Sabra, for their help in collecting and maintaining the mosquito field populations in the laboratory and for other laboratory work.}

\section{Authors' contributions}

$\mathrm{AH}$ designed the experiment. AH and NA performed the experiment. AH and $\mathrm{NA}$ analysed the data and wrote the manuscript. AH reviewed and edited the final manuscript. All authors read and approved the manuscript.

\section{Funding}

This work was funded by the Deanship of Scientific Research at King Saud University through Research Group number G-1441-480.

\section{Availability of data and materials}

The datasets generated and/or analysed during the present study are available from the corresponding author on reasonable request.

\section{Declarations}

Ethics approval and consent to participate

Not applicable.

\section{Consent for publication}

Not applicable.

\section{Competing interests}

The authors declare that they have no competing interests.

Received: 2 June 2021 Accepted: 15 October 2021

Published online: 29 October 2021

References

1. Shah RM, Alam M, Ahmad D, Waqas M, Ali Q, Binyameen M, et al. Toxicity of 25 synthetic insecticides to the field population of Culex quinquefasciatus Say. Parasitol Res. 2016;115:4345-51.

2. Amorim LB, Helvecio E, de Oliveira CMF, Ayres CFJ. Susceptibility status of Culex quinquefasciatus (Diptera: Culicidae) populations to the chemical insecticide temephos in Pernambuco, Brazil. Pest Manag Sci. 2013;69:1307-14.

3. World Health Organisation. Global programme to eliminate lymphatic filariasis: progress report on mass drug administration, 2010. Weekly Epidemiol Rec. 2011:86:377-87.

4. Nitatpattana N, Apiwathnasorn C, Barbazan P, Leemingsawat S, Yoksan S, Gonzalez J. First isolation of Japanese encephalitis from Culex quinquefasciatus in Thailand. SE Asian J Trop Med Public Health. 2005;36:875.

5. Hemida MG, Perera RAPM, Chu DKW, Ko RLW, Alnaeem AA, Peiris M. West Nile virus infection in horses in Saudi Arabia (in 2013-2015). Zoonoses Public Health. 2019;66:248-53.

6. Su T, Webb JP, Meyer RP, Mulla MS. Spatial and temporal distribution of mosquitoes in underground storm drain systems in Orange County, California. J Vector Ecol. 2003;28:79-89. 
7. Shah RM, Ali Q, Alam M, Shad SA, Majeed S, Riaz M, et al. Larval habitat substrates could affect the biology and vectorial capacity of Culex quinquefasciatus (Diptera: Culicidae). J Med Entomol. 2017;54:638-45.

8. Joseph AO, Adepeju SOI, Omosalewa OB. Distribution, abundance and diversity of mosquitoes in Akure, Ondo State, Nigeria. J Parasitol Vector Biol. 2013;5:132-6.

9. Benelli $\mathrm{G}$, Jeffries $\mathrm{CL}$, Walker T. Biological control of mosquito vectors: past, present, and future. Insects. 2016;7:52.

10. Lees RS, Gilles JR, Hendrichs J, Vreysen MJ, Bourtzis K. Back to the future: the sterile insect technique against mosquito disease vectors. Curr Opin Insect Sci. 2015;10:156-62.

11. Liu H, Cupp EW, Micher KM, Guo A, Liu N. Insecticide resistance and cross-resistance in Alabama and Florida strains of Culex quinquefaciatus. J Med Entomol. 2004;41:408-13.

12. McCarroll L, Hemingway J. Can insecticide resistance status affect parasite transmission in mosquitoes? Insect Biochem Mol Biol. 2002;32:1345-51.

13. Abbas N, Hafez AM. Resistance to insect growth regulators and agestage, two-sex life table in Musca domestica from different dairy facilities. PLoS ONE. 2021;16:e0248693.

14. Darriet F, Corbel V. Laboratory evaluation of pyriproxyfen and spinosad, alone and in combination, against Aedes aegypti larvae. J Med Entomol. 2006;43:1190-4.

15. Campos KB, Martins AJ, de Melo RC, Bellinato DF, dos Santos DL, da Graça Macoris MDL, et al. Assessment of the susceptibility status of Aedes aegypti (Diptera: Culicidae) populations to pyriproxyfen and malathion in a nation-wide monitoring of insecticide resistance performed in Brazil from 2017 to 2018. Parasit Vectors. 2020;13:1-18.

16. Shetty V, Sanil D, Shetty NJ. Insecticide susceptibility status in three medically important species of mosquitoes, Anopheles stephensi, Aedes aegypti and Culex quinquefasciatus, from Bruhat Bengaluru Mahanagara Palike, Karnataka. India Pest Manag Sci. 2013;69:257-67.

17. Rai P, Bharati M, Subba A, Saha D. Insecticide resistance mapping in the vector of lymphatic filariasis, Culex quinquefasciatus Say from northern region of West Bengal, India. PLOS ONE. 2019;14:e0217706.

18. Delannay C, Goindin D, Kellaou K, Ramdini C, Gustave J, Vega-Rúa A. Multiple insecticide resistance in Culex quinquefasciatus population from Guadeloupe (French West Indies) and associated mechanisms. PLOS ONE. 2018;13:e0199615.

19. Alam M, Waqas Sumra M, Ahmad D, Shah RM, Binyameen M, Ali SS. Selection, realized heritability, and fitness cost associated with dimethoate resistance in a field population of Culex quinquefasciatus (Diptera: Culicidae). J Econ Entomol. 2017;110:1252-8.

20. Jinguji H, Ohtsu K, Ueda T, Goka K. Effects of short-term, sublethal fipronil and its metabolite on dragonfly feeding activity. PLOS ONE. 2018;13:e0200299.

21. Saeed R, Abbas N, Razaq M, Mahmood Z, Naveed M, Rehman HMU. Field evolved resistance to pyrethroids, neonicotinoids and biopesticides in Dysdercus koenigii (Hemiptera: Pyrrhocoridae) from Punjab, Pakistan. Chemosphere. 2018;213:149-55.

22. Abbas N, Shad SA, Ismail M. Resistance to conventional and new insecticides in house flies (Diptera: Muscidae) from poultry facilities in Punjab, Pakistan. J Econ Entomol. 2015;108:826-33.

23. Reissert-Oppermann S, Bauer B, Steuber S, Clausen PH. Insecticide resistance in stable flies (Stomoxys calcitrans) on dairy farms in Germany. Parasitol Res. 2019;118:2499-507.

24. Lau KW, Chen CD, Lee HL, Norma-Rashid Y, Sofian-Azirun M. Evaluation of insect growth regulators against field-collected Aedes aegypti and Aedes albopictus (Diptera: Culicidae) from Malaysia. J Med Entomol. 2015:52:199-206.

25. Bellinato DF, Viana-Medeiros PF, Araújo SC, Martins AJ, Lima JBP, Valle D. Resistance status to the insecticides temephos, deltamethrin, and diflubenzuron in Brazilian Aedes aegypti populations. Biomed Res Int. 2016:2016:8603263.

26. Insecticide Resistance Action Committee (IRAC). Mode of action classification scheme, version 9.4. www.irac-online.org/documents/moaclassification. Accessed Apr 2020.

27. Cordova D, Benner E, Sacher M, Rauh J, Sopa J, Lahm G, et al. Anthranilic diamides: a new class of insecticides with a novel mode of action, ryanodine receptor activation. Pestic Biochem Physiol. 2006;84:196-214.
28. Shah RM, Shad SA. House fly resistance to chlorantraniliprole: cross resistance patterns, stability and associated fitness costs. Pest Manag Sci. 2020;76:1866-73

29. Lahm GP, Stevenson TM, Selby TP, Freudenberger JH, Cordova D, Flexner $L$, et al. Rynaxypyr ${ }^{\mathrm{TM}}$ : a new insecticidal anthranilic diamide that acts as a potent and selective ryanodine receptor activator. Bioorg Med Chem Lett. 2007;17:6274-9.

30. Liu Y, Gao Y, Liang G, Lu Y. Chlorantraniliprole as a candidate pesticide used in combination with the attracticides for lepidopteran moths. PLoS ONE. 2017;12:e0180255.

31. Santos VSV, Limongi JE, Pereira BB. Association of low concentrations of pyriproxyfen and spinosad as an environment-friendly strategy to rationalize Aedes aegypti control programs. Chemosphere. 2020;247:125795

32. World Health Organisation. Monitoring and managing insecticide resistance in Aedes mosquito populations: interim guidance for entomologists. Geneva: World Health Organisation; 2016. https://apps.who.int/iris/ handle/10665/204588. Accessed Jan 2020.

33. Robertson JL, Savin N, Preisler HK, Russell RM. Bioassays with arthropods. Boca Raton: CRC Press; 2007.

34. LeOra S. Poloplus, a user's guide to probit or logit analysis. Berkeley: LeOra Software; 2003.

35. Abbott W. A method of computing the effectiveness of an insecticide. J Econ Entomol. 1925;18:265-7.

36. Litchfield JT, Wilcoxon F. A simplified method of evaluating dose-effect experiments. J Pharmacol Exp Ther. 1949;96:99-113.

37. Mazzarri MB, Georghiou GP. Characterization of resistance to organophosphate, carbamate, and pyrethroid insecticides in field populations of Aedes aegypti from Venezuela. J Am Mosq Control Assoc. 1995;11:315-22.

38. Lopes RP, Lima JBP, Martins AJ. Insecticide resistance in Culex quinquefasciatus Say, 1823 in Brazil: a review. Parasit Vectors. 2019;12:1-12.

39. Abbas N, Abubakar M, Hassan MW, Shad SA, Hafez AM. Risk assessment of flonicamid resistance in Musca domestica (Diptera: Muscidae): resistance monitoring, inheritance, and cross-resistance potential. J Med Entomol. 2021;58:1779-87.

40. Kristensen M, Jespersen JB. Larvicide resistance in Musca domestica (Diptera: Muscidae) populations in Denmark and establishment of resistant laboratory strains. J Econ Entomol. 2003;96:1300-6.

41. Acevedo GR, Zapater M, Toloza AC. Insecticide resistance of house fly, Musca domestica (L.) from Argentina. Parasitol Res. 2009;105:489-93.

42. Bell HA, Robinson KA, Weaver RJ. First report of cyromazine resistance in a population of UK house fly (Musca domestica) associated with intensive livestock production. Pest Manag Sci. 2010;66:693-5.

43. Abbas N, Shad SA, Shah RM. Resistance status of Musca domestica L. populations to neonicotinoids and insect growth regulators in Pakistan poultry facilities. Pak J Zool. 2015;47:1663-71.

44. Khan HAA, Akram W, Arshad M, Hafeez F. Toxicity and resistance of field collected Musca domestica (Diptera: Muscidae) against insect growth regulator insecticides. Parasitol Res. 2016;115:1385-90.

45. Levot GW. Cyromazine resistance detected in Australian sheep blowfly. Aust Vet J. 2012;90:433-7.

46. James PJ, Cramp AP, Hook SE. Resistance to insect growth regulator insecticides in populations of sheep lice as assessed by a moulting disruption assay. Med Vet Entomol. 2008;22:326-30.

47. Grigoraki L, Puggioli A, Mavridis K, Douris V, Montanari M, Bellini R, et al. Striking diflubenzuron resistance in Culex pipiens, the prime vector of West Nile Virus. Sci Rep. 2017;7:1-8.

48. Belinato TA, Martins AJ, Lima JBP, Valle D. Effect of triflumuron, a chitin synthesis inhibitor, on Aedes aegypti, Aedes albopictus and Culex quinquefasciatus under laboratory conditions. Parasit Vectors. 2013;6:1-7.

49. Khan HAA, Shad SA, Akram W. Resistance to new chemical insecticides in the house fly, Musca domestica L., from dairies in Punjab, Pakistan. Parasitol Res. 2013;112:2049-54.

50. Fotakis EA, Mastrantonio V, Grigoraki L, Porretta D, Puggioli A, Chaskopoulou A, et al. Identification and detection of a novel point mutation in the Chitin Synthase gene of Culex pipiens associated with diflubenzuron resistance. PLoS Negl Trop Dis. 2020;14:e0008284.

51. Fang Y, Tambo E, Xue J-B, Zhang Y, Zhou X-N, Khater El. Molecular analysis of targeted insecticide resistance gene mutations in field-caught mosquitos of medical importance from Saudi Arabia. J Med Entomol. 2021;58:1839-48 
52. de Araújo AP, Paiva MHS, Cabral AM, Cavalcanti AEHD, Pessoa LFF, Diniz DFA, et al. Screening Aedes aegypti (Diptera: Culicidae) populations from Pernambuco, Brazil for resistance to temephos, diflubenzuron, and cypermethrin and characterization of potential resistance mechanisms. J Insect Sci. 2019;19:16.

53. Alsheikh A, Mohammed W, Noureldin E, Daffalla O, Shrwani K, Hobani Y, et al. Resistance status of Aedes aegypti to insecticides in the Jazan Region of Saudi Arabia. Biosci Biotech Res Asia. 2016;13:155-62.

54. Zhang X, Liao X, Mao K, Yang P, Li D, Alia E, et al. The role of detoxifying enzymes in field-evolved resistance to nitenpyram in the brown planthopper Nilaparvata lugens in China. Crop Prot. 2017;94:106-14.
55. Estep AS, Sanscrainte ND, Waits CM, Louton JE, Becnel JJ. Resistance status and resistance mechanisms in a strain of Aedes aegypti (Diptera: Culicidae) from Puerto Rico. J Med Entomol. 2017;54:1643-8.

56. Yezli S, Shibl AM, Livermore DM, Memish ZA. Antimicrobial resistance among Gram-positive pathogens in Saudi Arabia. J Chemother. 2012;24:125-36.

\section{Publisher's Note}

Springer Nature remains neutral with regard to jurisdictional claims in published maps and institutional affiliations.
Ready to submit your research? Choose BMC and benefit from:

- fast, convenient online submission

- thorough peer review by experienced researchers in your field

- rapid publication on acceptance

- support for research data, including large and complex data types

- gold Open Access which fosters wider collaboration and increased citations

- maximum visibility for your research: over $100 \mathrm{M}$ website views per year

At BMC, research is always in progress.

Learn more biomedcentral.com/submissions 